\title{
Einladung zur Mitgliederversammlung im Rahmen der 60. Jahrestagung der Deutschen Gesellschaft für Phlebologie vom 20.9.2019, 16.45 Uhr in Münster
}

Sehr geehrte Frau Kollegin, sehr geehrter Herr Kollege, im Namen unseres Präsidenten, Herrn Professor Dr. med. M. Stücker, lade ich Sie herzlich zur Mitgliederversammlung ein.

\section{Ort: Halle Münsterland}

Datum: Freitag, 20. September 2019, 16.45-18.15 Uhr, Weisser Saal

\section{Tagesordnung:}

1. Gedenken der Verstorbenen

2. Genehmigung der Tagesordnung
3. Genehmigung des Protokolls der Mitgliederversammlung vom 28.9.2018 in Bielefeld (veröffentlicht in Phlebologie 6/2018)

4. Bericht des Präsidenten

5. Bericht der Generalsekretärin

6. Bericht des Schatzmeisters

a) Bericht der Kassenprüfer

b) Entlastung des Vorstandes

7. Wahlen

8. Berichte der Kongresspräsidenten

- 2020

- 2021

$-2022$
9. Forschungsförderungskommission und Forschungsbericht

10. Bericht aus dem Berufsverband

11. Leitlinien

12. Fortbildungsakademie der Deutschen Gesellschaft für Phlebologie

13. Bericht aus der Zeitschrift Phlebologie

14. Berichte aus den Kommissionen und Arbeitsgemeinschaften

15. Verschiedenes

gez.

Dr. med. E. Mendoza

Generalsekretärin 